\title{
Demosntrativos e o fio do discurso
}

\author{
Sílvia Helena Barbi Cardoso \\ Universidade Federal de Uberlândia
}

\section{Abstract}

Linguistic as well as phylosophical tradition do not take into account a discoursive level of reference, necessarily ideological, that determines the 'exoforic' or 'anaphoric' deixis. From the analysis of the demonstrative pronouns of spoken Portuguese, this work proposes that the demonstrative pronouns, functioning either as determiners or as noun phrases as a whole, constitute a privileged place of contact that the discourse event keeps with its specific exterior or with its interdiscoursive domain. 


\section{INTRODUÇÃO}

A análise dos demonstrativos do discurso oral nos revela a existência de um funcionamento discursivo, muito mais com

1 plexo do que o funcionamento semântico-sintático com que a tradição tem procurado explicar os demonstrativos anafóricos, e muito mais complexo, ainda, do que o funcionamento pragmático, utilizado para explicar os demonstrativos dêiticos.

$O$ objeto deste trabalho é mostrar que esse funcionamento discursivo dos demonstrativos do discurso oral coloca em questão a unicidade do texto, ou a noção de "fio do discurso", além de deslocar a idéia de coesão-coerência textual para a noção discursiva de heterogeneidade constitutiva.

Os exemplos aqui apresentados fazem parte de uma pesquisa maior (Cardoso, 1994), em que são analisados os demonstrativos de alguns inquéritos do Projeto NURC SP (DID 18, DID 343, EF 405, D2 62) e do discurso do ex-presidente Fernando Collor de Mello, de 04/04/91, em que o ex-presidente declarou à nação ter nascido com aquilo roxo.

\section{ANÁFORA E PRESSUPOSIÇĀO}

Muitos autores, como Sériot (1985), têm defendido que a anáfora nominal repousa sobre um efeito de pressuposição, ou seja, que a reprise anafórica, num determinado discurso, não é estabelecida por um determinado signo formal, mas por um ato de reconhecimento, ou por um funcionamento "endoxal", correspondente ao que Aristóteles chamava "doxa", ou opinião comum.

Esse funcionamento "endoxal" da anáfora nominal é concebido, 
muitas vezes, por oposição ao funcionamento da anáfora pronominal. Veja-se, por exemplo, que logo após afirmar (pág.151) que a fonte do doxa é um funcionamento e não a natureza das unidades, Sériot nega que o doxa possa funcionar quando a anáfora for pronominal:

"Ainsi, à la différence des pronoms, rien dans un nom ne permet de lui reconnaître par une seule analyse intratextuelle, formelle, le statut d'anaphore”. (Sériot, 1985:151)

Mais adiante:

"Parler d'anaphore comme rappel (au niveau pressupposé) de ce qui a été dit avant aligne l'anaphore nominale sur l'anaphore pronominale. C'est à dire qu'en ne parlant que de reprise, on ne pose pas le problème de ce qui est perdu ou modifié dans le passage de l'antécédent à son anaphore." (Sériot, 1985:156)

Sériot é fiel à mais autêntica tradição francesa. Basta lembrar que para Benveniste (1966), que considera a questão anafórica apenas com referência aos pronomes (de acordo com uma tradição que remonta a Apolônio Díscolo, na Grécia Antiga), a anáfora pronominal é um fenômeno sintático, pertencendo ao domínio daquilo que o lingüista categorizou como "terceira pessoa". A "terceira pessoa", na qual Benveniste inclui todo o sistema anafórico da língua, cumpre uma função referencial representacional ou constativa, por oposição à primeira e à segunda pessoas, que cumprem uma função enunciatória ou discursiva.

Ora, conforme desejo argumentar, esse funcionamento discursivo de referência anafórica não é privilégio da anáfora nominal. É igualmente válido para os casos de anáfora pronominal, que a língua em uso não se cansa de exibir. Um exame mais acurado dos demonstrativos vai mostrar que os demonstrativos anafóricos, de "terceira pessoa", cumprem igualmente uma função enunciatória, discursiva. Sua 
referência não é determinada por um mecanismo sintático independente, como querem Benveniste e Sériot, mas por um mecanismo discursivo, em cuja base está uma pressuposição. Daí ser possível afirmar que a anáfora (demonstrativa) pronominal, tanto quanto a nominal, tem como base uma pressuposição.

Examinando-se os sintagmas determinados por demonstrativos no discurso oral, é possível observar-se a validade do postulado segundo o qual a anáfora é um processo discursivo, "endoxal", que extrapola o domínio da sintaxe e da semântica do texto. O exemplo (1) parece indicar que somente um saber extra-lingüístico, partilhado entre os interlocutores, ou mais exatamente, um "efeito de saber", permite postular a identidade referencial dos itens destacados:

(1) "Vocês sabem como é dificil para o nordestino se firmar no cenário nacional. Saí do governo de Alagoas, dois anos e dois meses de governo, lutando contra os poderosos, contra aqueles que humilhavam o nosso povo." (discurso do Presidente)

O exemplo em questão indica ainda que marcas formais, como as marcas de gênero e número, não garantem a co-referência.

$O$ reconhecimento da co-referencialidade anafórica corresponde, em muitos casos, a um apagamento de diferenças que seriam contudo relevantes em outros discursos, o que pode ser evidenciado pelos exemplos abaixo:

(2) "Eu sei que todos vocês querem, porque este é um sentimento de Norte a Sul, de Leste a Oeste do país, o povo está querendo que suas lideranças politicas encontrem formas $e$ maneiras de poder conviver, de uma forma que traga beneficios e bem estar social para a nossa população carente." (discurso do Presidente)

(3) "deixar apenas o alicerce, para partir do alicerce bem feito, construir uma nova sociedade, construir um novo Bra- 
sil, mais justo, mais fraterno, mais solidário, e é exatamente, minha gente, nesta toada que nós estamos caminhando." (discurso do Presidente)

No exemplo (2), é possível afirmar a co-referencialidade de "a vontade do povo" e "um sentimento", assim como, no exemplo (3), é possível afirmar a co-referencialidadade de "deixar apenas o alicerce bem feito para a partir dele construir uma nova sociedade e um novo país" e "uma toada". No entanto, fora do contexto específico em que esses exemplos ocorrem (ou, de acordo com Foucault, 1969, fora dessa formação discursiva), afirmar tal tipo de co-referencialidade poderia equivaler a compactuar com o absurdo ou com a incoerência em diversos graus.

Uma outra questão a ser considerada, é que o funcionamento anafórico repousa quase sempre sobre uma predicação implícita: sob a aparência de uma simples reprise, de uma simples substituição, a segunda menção é quase sempre uma predicação, de modo que a anaforização, que é em princípio um fator de coerência textual, mascara com efeito a adjunção de uma informação, que permite fazer o texto caminhar numa nova direção. Assim, nos exemplos de (1) a (3), a "reprise" anafórica repousa sobre as seguinte predicaçбes: "os poderosos humilhavam o nosso povo", "a vontade do povo é um sentimento", "construir um novo país é uma toada".

\subsection{ANÁFORA NEUTRA E PRESSUPOSIÇÃO}

O "funcionamento endoxal" da anáfora pronominal é extensivo aos casos com pronome neutro, lexicalmente vazio. Os pronomes neutros, por não oferecerem qualquer pista lexical para a identificação do referente, são bastante dependentes da recorrência a fatores situacionais, discursivos e interpretativos.

Uma das particularidades da anáfora neutra é a possibilidade de retomar conteúdos de extensão muito variada, os quais ultrapassam, na maioria das vezes, os limites de um constituinte de sentença, como também os limites da sentença. A "medida" do antecedente (ou con- 
seqüente) vai depender de fatores que se pressupõem na interlocução, conforme se pode observar no exemplo (4):

(4) “...o povo está querendo que as suas lideranças políticas encontrem formas e maneiras de poder conviver, de uma forma que traga beneficios e bem estar social para a nossa população carente, e é exatamente isso que nós estamos aqui promovendo, o entendimento das diversas fações politicas do pais e do Nordeste." (discurso do Presidente)

Há, nesse exemplo, muitos candidatos a referente do pronome isso: 1 . o contexto lingüístico anterior "benefícios... a nossa população carente"; 2. o contexto lingüistico anterior "as suas lideranças...carente"; 3 . o contexto lingüistico posterior "o entendimento...Nordeste"; 4 . o contexto lingüístico anterior "as suas lideranças políticas...a nossa população carente" e posterior "o entendimento...Nordeste" ao mesmo tempo.

A decisão pela última possibilidade (o contexto lingüístico anterior e posterior ao mesmo tempo "as suas lideranças políticas...a nossa população carente", "o entendimento...Nordeste"), que parece resultar numa boa leitura, advém da mobilização de fatores discursivos, que levam a identificar o referente de isso com "a vontade do povo".

A interpretação do referente de isso como "a vontade do povo" pressupõe uma base comum de significação para: "a convivência das lideranças políticas", "o benefício e o bem-estar social da população carente", "o entendimento das diversas facçðes políticas do país".Uma vez admitido com Frege (1892) que não há referência universalmente aceita para "a vontade do povo", ou seja, que "a vontade do povo" é uma expressão referencialmente ambígua, de onde vem então a identificação dos elementos acima apontados com "a vontade do povo"?

No interior dos discursos demagógicos, populistas, de que o discurso do Presidente parece ser um exemplar perfeito, "povo", "a vontade do povo", são expressões que são empregadas contudo como se tivessem uma referência unívoca e estável, e são quase sempre 
associadas a uma rede de expressões, tais como: "população carente" - aquilo que a maioria do povo (brasileiro) é e não deseja ser; "benefícios", "bem-estar social" - aquilo que o povo deseja receber através da ação político-administrativa de seus governantes; "entendimento", "bom-senso", "razão", "diálogo" - aquilo que o povo deseja para os representantes do poder.

O princípio que fundamenta essa análise é o da paráfrase e sinonímia (ver Fuchs, 1982).

É possível que se diga que as expressóes em questão (a convivência das lideranças políticas, o benefício e o bem-estar social da população carente, o entendimento das diversas facções políticas do país) não estão numa relação interparafrástica, argumentando-se que eles não constroem as mesmas significações, pois, embora possam ter o mesmo referente, não têm o mesmo sentido. No entanto, a "obviedade" na semelhança de sentido dos enunciados nem sempre é um fenômeno estritamente lingüístico. Em outras palavras: uma relação interparafrástica não é um fato independente do discurso, um fato dado pela língua, através de semelhanças entre a significação das palavras ou das construções gramaticais. A relevância ou a irrelevância da diferença existente entre as expressões e os enunciados depende quase sempre de um julgamento de quem produz e de quem interpreta.

Outro exemplo: no exemplo (5) isso pode ter como referente: 1. apenas o contexto linguístico posterior "eu havia nascido com aquilo roxo"; 2 . o contexto linguístico anterior e posterior ao mesmo tempo "não nasci com medo de assombração, nem tenho medo de cara feia", "eu havia nascido com aquilo roxo". A decisão dependerá de fatores discursivos.

(5) "Vocês me conhecem, e sabem que eu sou homem de enfrentar desafios, eu enfrento todos os desafios que foram colocados diante de mim, não nasci com medo de assombração, nem tenho medo de cara feia, isso o meu pai já dizia, desde quando eu era pequeno, que eu havia nascido com aquilo roxo, e tenho mesmo para enfrentar todos aque- 
les que querem conspirar contra o processo democrático." (discurso do Presidente)

A questão da referência de isso, no exemplo em questão, é a de se poder determinar o que de fato disse o pai do locutor (segundo o próprio locutor). A interpretação 1., segundo a qual o pai do locutor haveria dito (apenas) que seu filho nasceu com "aquilo roxo" é uma interpretação possível e se ajusta à pressuposição possível de ser feita do paternal orgulho machista brasileiro, um pressuposto ideológico, traduzido através da conhecida expressão popular "nascer com o saco roxo". No entanto, é possível pressupor-se, também, uma relação de causa e feito entre "nascer com "aquilo" roxo" e "não ter medo de assombração ou de cara feia": "não tem medo de assombração ou de cara feia (efeito) porque nasceu com "aquilo" roxo (causa)". Nesse caso, a interpretação 2 . é a que mais se ajusta ao pressuposto ideológico em questão.

Neste outro exemplo (6), isso parece anaforizar uma vasta área textual, de "investir maciçamente no nordeste" a "prosperidade para a população nordestina":

(6) "Eu não acredito que possamos construir um Brasil desenvolvido se nós não pudermos investir maciçamente no Nordeste, e investimento tem de ser, minha gente, para permitir a implantação de novas indústrias, para desenvolver pólos industriais, de modo a que esses pólos gerem empregos, gerem renda, distribuição de riqueza, enfim, progresso e prosperidade para a população nordestina.É exatamente isso que nós estamos tratando de fazer..." (discurso do Presidente)

A interpretação proposta mobiliza diversos fatores. Demanda considerar "o investimento (maciço no Nordeste)" hiperônimo de: "a implantação de novas indústrias", "o desenvolvimento de pólos industriais", "a geração de empregos", "a geração de renda", "a distribuição de riqueza", "o progresso", "a prosperidade (para a popula- 
ção nordestina)", e fora da condicional do contexto anterior ("se nós não pudermos investir maciçamente no Nordeste"). A hiperonímia em questão é prevista no interior dos discursos neo-liberiais, em que "investimento", "progresso", "igualdade social" e "desenvolvimento industrial" estão em relação parafrástica. $O$ apagamento da condicional e a substituição do subjuntivo negativo ("não pudermos"), expressão de dúvida, incerteza (atitude subjetiva do falante), pelo indicativo presente ("estamos tratando de fazer" = "estamos investindo"), expressão de certeza, são garantidos por um jogo de pressuposições, das quais uma é a imagem positiva que o Presidente (nordestino) faz de si mesmo e de seu governo e que pressupðe que seu alocutário (nordestino) também faça.

Os exemplos com anáfora demonstrativa neutra do discurso oral nos alertam para a necessidade de rompermos, de uma vez por todas, com essa tradição que insiste em manter o nível referencial dos pronomes anafóricos, ditos "substitutos", fora das coordenadas pressuposicionais da enunciação.

\section{A EXÓORA PRESSUPOSICIONAL}

Nos casos de funcionamento exofórico dos demonstrativos, é possivel igualmente reconhecer a existência de um funcionamento discursivo "endoxal", que pode ser visto como um caso de anáfora potencial, se considerarmos a pressuposição enquanto um enunciado que não é necessário afirmar, na medida que já é dado à interlocução. Nesse caso, a anáfora pronominal não estará remetendo a uma anterioridade material no contexto lingüístico à esquerda (ou à direita, caso que Halliday e Hasan, 1976, chamaram de "catáfora"), mas estará remetendo a uma exterioridade específica àquilo que constitui o universo de referência do discurso. Trata-se da relação do discurso que se constitui na interlocução com uma anterioridade/exterioridade discursiva, o que equivale a dizer, com 0 interdiscurso, o qual, formado por um conjunto de enunciados pertencentes a uma determinada época e a um grupo social determinado, é a condição de existência do próprio discurso (Pếcheux, 1975). 


\subsection{EXÓFORA PRESSUPOSICIONAL, POLIFONIA, HETEROGENEIDADE}

Antes de ilustrar com exemplos o funcionamento "endoxal" dos demonstrativos exofóricos, gostaria de apresentar uma forma de enriquecer essa análise.

A noção de pressuposição, cuja importância é considerável para as teorias do discurso, pode ser enriquecida se encarada como um fato de polifonia. A relação entre polifonia e pressuposição foi estabelecida por Berrendonner (1981). Por trás da reformulação da pressuposição como um fato de polifonia, como afirma Maingeneau (1987), pode-se ler uma reorientação da "verdade" dos enunciados, através da introdução do "agente verificador de Berrendonner", a instância posta como responsável, fiadora da validade do enunciado. Entretanto, como faz ver Maingeneau, a introdução de agentes verificadores não desemboca verdadeiramente sobre a uma concepção polifônica da pressuposição. É somente com Ducrot (1984 e 1989) que o princípio da pressuposição será encarado como uma pluralidade de fontes enunciativas, de modo a enriquecer sobremodo a análise lingüística.

A teoria polifônica de Ducrot, que constitui uma extensão (bastante livre) à lingüística dos trabalhos de Bakhtin sobre a literatura, $\mathrm{e}$ que muito deve a Authier e Plénat, segundo o próprio autor reconhece, denuncia a "evidência" do sujeito, ou seja, a crença de que cada enunciado possui um e somente um autor.

O objeto de uma concepção polifônica do sentido é, segundo Ducrot, mostrar como o enunciado assinala, em sua enunciação, a superposição de diversas vozes. A enunciação é o fato de o enunciado aparecer, e se constitui de um sujeito falante, que é um ser empírico, um locutor, que é o ser do discurso, e um locutor enquanto pessoa do mundo. Além desses elementos, existem os enunciadores, seres que são considerados como se expressando através da enunciação, sem que para tanto se lhe atribuam palavras precisas: se eles "falam", é somente no sentido em que a enunciação é vista como expressando seu ponto de vista, sua posição, sua atitude, 
mas não no sentido material do termo, suas palavras.

Segundo desejo argumentar, os conceitos de locutor e enunciador, formulados por Ducrot, podem ter um inigualável valor operacional para a análise do discurso, e, no caso específico deste trabalho, servem para elucidar um dos empregos do demonstrativo no discurso, emprego totalmente ignorado pela tradição lingüística e filosófica e que venho chamando de exofbrico pressuposicional. No entanto, para que tenham esse valor, é necessário que se cruze a noção de historicidade, que estava originalmente presente no conceito de polifonia de Bakhtin, com o conceito de enunciador, formulado por Ducrot.

O quadro teórico de Ducrot dá conta do locutor, que para ele é "um ser do discurso, pertencente ao sentido do enunciado, e resultante desta descrição que o enunciado dá de sua enunciação" (pág. 195), mas não dá conta da enunciação dos enunciadores. A meu ver, a incapacidade de suplantar as dificuldades da enunciação dos enunciadores no quadro de uma construção teórica é decorrente do conceito monovalente de historicidade em Ducrot.

Ducrot inscreve sua teoria polifônica no domínio da "pragmática lingüística" ou "semântica", recusando-se a dar um salto maior, discursivo, de modo a inscrever a polifonia num domínio mais abrangente que extrapole as rígidas fronteiras daquilo que ele considera "propriamente lingüístico".

Considerando a enunciação apenas enquanto um acontecimento constituído pelo aparecimento de um enunciado, um acontecimento histórico, histórico enquanto uma "aparição momentânea", independente do jogo de influências sociais que a condiciona (dada a preocupação com o"propriamente lingüístico"!), independente de outras enunciaçбes, e independente, ainda, da noção de ato (um conceito de enunciação "que não encerre em si, desde o início, a noção de sujeito falante” (pág. 169)), Ducrot ignora um elemento relevante para a compreensão da verdadeira trama polifônica do discurso, ou seja, ignora a relação do discurso com o interdiscurso. Em outras palavras: falta na abordagem polifônica de Ducrot a consideração do eixo histórico "vertical", da memória, ocultado pelo eixo horizontal (Courtine, 
1981, Maingeneau, 1987), ou o eixo da "ideologia antes de nós" (Ricouer, 1977), no qual, a meu ver, devem estar situadas as "entidades" a que Ducrot chama de enunciadores.

Segundo a hipótese da referência discursiva, aqui defendida, o demonstrativo no seu emprego exofórico pressuposicional, como no exemplo (7), remete a uma anterioridade/exterioridade discursiva , ou ao espaço histórico vertical da memória (espaço constitutivo do discurso e que não precisa efetivamente ser dito), e, ao mesmo tempo, introduz uma voz outra que não a do um enunciador, marcando a heterogeneidade do discurso:

(7) para eu poder...pegar as conduções é muito dificultoso é aquele corre-corre (D2 SP 62:14)

Esse funcionamento, que parece pôr em causa a noção de coesão-coerência em função da noção de heterogeneidade enunciativa, constitutiva de todo discurso, se manifesta com extrema riqueza na língua oral:

(8) para fazer uma obra de arte... mais ou menos... a gente se dispõe... a gente pára aquela vida cotidiana da gente... EF SP 405:157)

(9) Doc. sim...agora...do milho na fazenda não se fazia nada?...só se vendia?

Inf. bom...fa::z fazem...fazem-se...esses doces tradicionais né? (DID SP 18:342)

(10) tanto que houve qquela...blá blá blá ai de::...desapropria ali o Colégio (D2 SP 343:417)

(11) nós entramos ali no aquele arroz unido venceremos (D2 $S P$ 62:227)

(12) não tem como apresentar uma justificativa de cobrar 
aquele preço que eles cobram (D2 SP 62:1314)

(13) então ele não tem aquela preocupação que NÓS brasileiros temos...o brasileiro tem aquela preocupação de ter a casa própria dele (D2 SP 62: 1163-1164)

(14) que existe nesse nesse clima aqui de São Paulo (D2 62:58)

Empregado fora da demonstração propriamente dita, e sem estar anaforizando um elemento anterior materialmente presente no contexto lingüístico, o demonstrativo nesse funcionamento exofórico pressuposicional (e, contudo, anafórico, se considerarmos a pressuposição como um enunciado dado na interlocução) parece ter a função de apontar para esse domínio do "não dito", de modo a unir o discurso que se constrói na interlocução com o interdiscurso no interior do qual se encontram elementos prévios, necessários para a constituição da referência.

A tradição lingüística e também a filosófica têm valorizado as pressuposiç̋̃es veiculadas por sintagmas nominais articulados. As pressuposiçð̃es veiculadas por demonstrativos são contudo ignoradas. Essa desconsideração talvez se deva ao fato de se entender que a função dos demonstrativos, "os signos mais dêiticos que existem", seja a de mostrar os referentes, de modo a garantir aquilo que se convencionou a chamar de função designativa da linguagem. Estender a pressuposição aos demonstrativos equivaleria a abalar as bases do único espaço referencial em que a linguagem poderia se relacionar diretamente com o mundo.

Desde as primeiras linhas deste trabalho, venho tentando dar um passo adiante, procurando colocar em causa esse fosso entre a função dos demonstrativos e os pressupostos discursivos, interpretativos, ideológicos.

Por outro lado, não estou pretendendo igualar as pressuposições veiculados pelos artigos e as veiculadas pelos demonstrativos. Os demonstrativos e os artigos não veiculam as mesmas pressuposições. 
Num primeiro momento pode parecer que nesse emprego pressuposicional fica comprometida a diferença entre o tradicional artigo e o tradicional demonstrativo. O demonstrativo seria, então, perfeitamente dispensável, podendo o artigo ser empregado em seu lugar:

(8') para fazer uma obra de arte... mais ou menos... a gente se dispõe... a gente pára a vida cotidiana da gente...

(9') Doc. sim...agora...do milho na fazenda não se fazia nada?...só se vendia?

Inf. bom...fa::z fazem...fazem-se...os doces tradicionais né?

(10') tanto que houve o...blá blá blá ai de::...desapropria ali o Colégio

(11') nós entramos ali no no arroz unido venceremos

(12') não tem como apresentar uma justificativa de cobrar o preço que eles cobram

(13') então ele não tem a preocupação que NÓS brasileiros temos...o brasileiro tem a preocupação de ter a casa própria dele

(14') que existe no no clima aqui de São Paulo

Isso contudo não é verdade. A substituição não é possível sem que se percam algumas coordenadas de referência. Nos exemplos com demonstrativos, não se pressupõe simplesmentea existência de "uma vida cotidiana da gente", de "doces tradicionais", de "um blá blá blá sobre a desapropriação do colégio", de "um tipo de arroz", de "a preocupação que os brasileiros têm de adquirir uma casa própria" etc. $O$ que está sendo trazido para o acontecimento discursivo, através do demonstrativo, são avaliações sociais, ideológicas, formulações de 
um interdiscurso, do tipo: "a vida cotidiana da gente é uma chatice", "os blá blá blás nunca dão em nada, são pura fofoca", "arroz papa é muito ruim, o melhor é o soltinho", "arroz papa é arroz de quem cozinha mal", "adquirir uma casa própria deve ser a primeira necessidade do brasileiro, já que quem não tem casa própria corre o risco de não poder sustentar-se num país dominado pela inflação" etc.

O locutor não é, contudo, obrigado a assumir como suas as formulaçбes pressupostas. Nos enunciados com demonstrativos fica mais evidente o distanciamento (no sentido de Authier-Revuz, 1982) entre o espaço enunciativo do discurso que se constitui na interlocução $e o$ interdiscurso do interior do qual se buscam elementos socialmente já avaliados para a constituição dos referentes. Numa abordagem polifônica, dir-se-ia que essas avaliações, pelas quais o locutor não se responsabiliza, podem ser atribuídas aos enunciadores anônimos do discurso.Isso equivale a dizer que nos exemplos com demonstrativos a heterogeneidade constitutiva do discurso é mais marcada. Daí o distanciamento. $\mathrm{O}$ demonstrativo é uma marca de herogeneidade, comparável talvez àquelas outras que em Authier-Revuz (1982) se reúnem sob a denominação de "conotação autonímica".

As freqüentes hesitações dos falantes não devem ser interpretadas como uma provável equivalência de $o$ e esse, mas como uma necessidade de ajuste, já que $o$ e esse não têm o mesmo valor referencial:

(15) tem tem o::aquele::...que faz uma pontinha lá...que tem esperança no futuro de ser um grande ator ou uma grande atriz... (D2 SP 62:1314)

(16) nós entramos ali no naquele arroz unido venceremos (D2 SP 62:227)

(17) e também mulheres participavam..e::iam...iam colhendo mesmo (18) ::...os aqueles chumaços de algodão e colocando no saco (DID SP 18:377) 
Pertencendo ao mesmo quadro de referência se situam os exemplos abaixo, nos quais o sintagma determinado pelo demonstrativo, que anaforiza um antecedente pressuposto, interdiscursivo, não necessita de qualquer adjetivação adicional além da determinação efetuada pelo próprio demonstrativo:

(18) L1 então quando foram fazer a Paulista...já tinham gastado três bi sei lá... cacetada de dinheiro

I

L2 com aquela rebal aquele rebaixamento né? (D2 SP 343:379)

(19) para eu poder... pegar as conduções é muito dificultoso é aquele corre-corre (D2 SP 62:14)

(20) está com um roupão lá um calor tremendo ai você tira a gravata tira isso...chega a tarde...aquela chuva aquele frio (D2 SP 62:37-38)

Também nesses casos o artigo e o demonstrativo não são intercambiáveis, porque, pelas mesmas razões apresentadas no caso anterior, as pressuposiç̋̃es não resultam as mesmas:

(18') L1 então quando foram fazer a Paulista...já tinham gastado três bi sei lá... cacetada de dinheiro

[

L2 com a reba/ o rebaixamento né?

(19') para eu poder...pegar as conduções é muito dificultoso é o corre-corre

(20') está com um roupão lá um calor tremendo aí você tira a gravata tira isso...chega a tarde... a chuva ofrio

Os exemplos com demonstrativos, em que não há nenhuma informação mais específica sobre o referente através de outros 
determinantes, revelam igualmente o domínio heterogêneo do interdiscurso. As vozes dos enunciadores, provindas do interior de um interdiscurso, se articulam, através dos demonstrativos, com a voz do locutor, que se responsabiliza pela enunciação, embora não tenha que se responsabilizar necessariamente pelas pressuposições veiculadas.

$\mathrm{O}$ valor referencial de aquele rebaixamento, aquele frio, aquela chuva, aquele corre-corre não é o mesmo de o rebaixamento, of frio, a chuva, o corre-corre. Com os demonstrativos não se trata de "aquilo que é rebaixamento", assim como não se trata de "aquilo que é chuva", ou "aquilo que é frio", ou "que é corre-corre". Também não se trata de uma simples pressuposição de conhecimento: "o rebaixamento da Paulista". Com os demonstrativos, qualifica-se, apreciase. Em outras palavras: a função do demonstrativo não é a de identificar um referente, ou melhor, um antecedente, como "chuva", "frio", "corre-corre" etc. Sua função é a trazer para o acontecimento discursivo, para ser (re)apreciado, um antecedente socialmente já apreciado: "o rebaixamento da Paulista que, como todo mundo sabe, demorou muito, consumiu muito dinheiro e não trouxe muito beneficio à população"; "o corre-corre do povo paulistano, que, como todo mundo sabe, faz o paulistano não ter tempo para isso ou aquilo"; "um frio que só faz mesmo em São Paulo", "um frio que só mesmo quem vive em São Paulo conhece", "São Paulo terra boa, São Paulo da garoa" etc.

Um exemplo do discurso do Presidente:

(21) "Minha gente amiga do Juazeiro, vocês podem estar certos de que eu estou em Brasilia, naquele Palácio do Governo, mas o meu coração e o meu pensamento estão voltados aqui para a minha terra..."

Poder-se-ia perguntar por que razão o Presidente não empregou $o \mathrm{em}$ vez de aquele. Uma resposta provável é que com o artigo perder-se-ia o valor apreciativo conferido pelo demonstrativo. $O$ e aquele são diferentes quanto a pressuposições que veiculam, conforme ve- 
nho afirmando. Com o emprego do artigo pressupõe-se que os interlocutores conheçam o palácio de que se fala como "o Palácio do Governo", situado em Brasília; com o demonstrativo, qualifica-se o palácio conhecido como "palácio longínquo", "estrangeiro", "longe de vocês, meu povo", "longe de minha gente". Esse valor referencial é confirmado pelo intradiscurso: "mas o meu coração e o meu pensamento estão voltados aqui para a minha terra, para o resto do Nordeste". O enunciado introduzido por mas rejeita o valor referencial de aquele, isto é, rejeita "longínquo", "distante de vocês, meu povo": "estou naquele Palácio do Governo, longe de meu povo, mas meu coração está perto". Em outras palavras: o escopo de mas, aquilo que ele rejeita, não é uma pressuposição de existência: "Palácio do Governo, que vocês conhecem (pelo menos de ouvir dizer)"; o que mas rejeita é a qualificação não dita, apenas pressuposta: "distante do meu povo".

\subsection{EXÓFORA PRESSUPOSICIONAL E MARCAS DE ORALIDADE}

Em se tratando de um trabalho que tem por escopo o discurso oral, não poderia ignorar, nessa discussão acerca da referência dos demonstrativos, o valor da entonação enfática, assim como de outros procedimentos usados na linguagem oral. Bakhtin (1929) já insistia que a entonação enfática, por ser um elemento constitutivo da referência, não deve ser tratada como um elemento marginal, adicional, a ser acoplado à significação, ou uma informação suplementar, relacionada ao sentimento íntimo do locutor, que se adiciona à informação puramente intelectual (referencial). Em outras palavras: ao se intensificar uma predicação, através da entonação enfática, ou outros processos, como o alongamento das vogais, essa intensificação está a serviço do processo de construção da referência pelo discurso.

No caso específico dos inquéritos analisados neste trabalho, um fato que deve chamar a atenção de um pesquisador atento, quando este entra em contato com as gravaçøes e suas respectivas transcrições, é a baixa incidência de demonstrativos exofóricos 
pressuposicionais marcados através dos processos de aumento de tom de voz e de alongamento de vogal (processos que, por serem muito próximos, podem ser considerados um conjunto correlacionado, como quer Marcuschi, 1994). Uma incidência, na verdade, baixíssima, considerando-se a existência de apenas dois casos em cinqüenta e três ocorrências, sendo que um dos casos deixa a dúvida de que se trata de fato de uma marca considerável, se levarmos em conta a idiossincrasia do falante, a velocidade e a altura média de sua fala. Outro fato, que também deve chamar a atenção do pesquisador, é que certos falantes do NURC, que costumam marcar muito o seu discurso, com entonação especial, não marcam os demonstrativos, nem mesmo os exofóricos pressuposicionais. A entonação especial é reservada mais comumente aos verbos e aos nomes.

Esses fatos parecem oferecer sustentação à hipótese sobre a referência dos demonstrativos exofóricos pressuposicionais, defendida neste trabalho: os demonstrativos, nesse emprego, não remetem a antecedentes supostamente conhecidos pelos interlocutores; remetem, outrossim, a antecedentes socialmente já avaliados, o que equivale a dizer que remetem principalmente a essas avaliações ou a pressupostos ideologicamente tão marcados que não necessitam de ser intensificados por marcas específicas. Daí o demonstrativo tira a sua originalidade e se diferencia do artigo. A pressuposição já é sua marca.

\section{CONCLUSĀo}

Minha intenção, ao mostrar que a anáfora pronominal demonstrativa, tanto quanto a anáfora por nominalização, é uma paráfrase discursiva, ou seja, uma forma de reavaliação discursiva de referentes, e não simplesmente um processo de derivação morfo-sintática, é estender o funcionamento da heterogeneidade constitutiva aos sintagmas determinados por demonstrativos e também aos sintagmas constituídos de demonstrativos "neutros", lexicalmente vazios. Isso equivale a dizer que a anáfora demonstrativa, tanto quanto a nominalização, constitui um lugar privilegiado de contato que o tex- 
to mantém com seu exterior específico ou com o domínio de sua referência. A heterogeneidade se evidencia, porém, de uma maneira mais evidente através dos demonstrativos exofóricos pressuposicionais, desconhecidos da tradição lingüística e filosófica, contudo bastante freqüentes no discurso oral. Nesse caso especifico, os demonstrativos parecem marcar um distanciamento maior entre os dois espaços enunciativos, ou seja, entre o que se enuncia na interlocução (no aqui e agora do acontecimento discursivo) e o que já está enunciado no interior do interdiscurso.

\section{REFERÊNCIAS BIBLIOGRÁFICAS}

Authier-Revuz, J., "Hétérogénéité montrée et hétérogéneité constitutive: éléments pour une aproche de l'autre dans le discours", in DRLAV, Paris, 26, pp. 91$151,1982$.

Bakhtin, M., Marxismo e filosofia da linguagem, $4^{n}$ ed., São Paulo, SP, Hucitec, 1988 (trad. bras.com base na trad. francesa, de 1977, do original russo de 1929)

Benveniste, E., "A natureza dos pronomes", in Problemas de Lingüística Geral I, $2^{2}$ ed., Campinas, SP, Pontes, pp. 277-83, 1988 (trad. bras. de Problèmes de linguistique générale, 1966)

Berrendonner, A. ,Éleménts de pragmatique linguistique, Paris, Éditions de Minuit, 1981.

Cardoso, S.H.B., Demonstrativo, dêixis e interdiscurso, tese de doutorado, UNICAMP, Campinas, SP, 1994.

Courtine, J.J. , “Analyse du discours politique”, in Langages, Paris, junho de 1981.

Ducrot, O., $O$ dizer e o dito, Campinas, SP, Pontes, 1987 (trad. bras. de Le Dire et le Dit, 1984).

, "Argumentação e "topoi" argumentativos", in História e sentido na linguagem, Eduardo Guimarăes (org.), Campinas, SP, Pontes, pp. 13-38, 1989.

Foucault, M., $A$ arqueologia do saber, $3^{\text {a }}$ ed., Rio de Janeiro, RJ, Forense-Universitária, 1987 (trad. bras. de L'archéologie du savoir, 1969). 
Frege, G., "Sobre o sentido e a referência", in Lógica e Filosofia da Linguagem, Paulo Alcoforado (org.), São Paulo, SP, Cultrix, pp. 61-103, 1978 (trad. bras. de "Über Sinn und Bedeutung", 1892).

Fuchs, C., "La paraphrase entre la langue et le discours", in Langue Française, Paris, 53, pp. 23-33, 1882.

Halliday, M. A. K. \& Hasan, Cohesion in English, London, Longman, 1976.

Maingeneau, D. , Novas tendências em análise do discurso, Campinas, SP, Pontes, 1989 (trad. de Nouvelles tendences en analyse du discours, 1987).

Marcuschi, L.A. , "O alongamento de vogal na produção textual falada", FPE (mimeogr.).

Pêcheux, M., Semântica e discurso: uma crítica à afirmação do óbvio, Campinas, SP, UNICAMP, 1988 (trad. de Les vérités de la Palice, 1975).

Ricouer, P., Interpretação e ideologias, Rio de Janeiro, RJ, Francisco Alves, 1977.

Sériot, P., "L'anaphore et le fil du discours (Sur l'interpretation des nominalisation en français et en russe), in Opérateurs syntaxiques et cohésion descursive, Henning Nolke (ed.), Nyt Nordish Forlag Arnold Buscj, pp. 147-160, 1985. 